\title{
Crossing the Borders Between Teaching, Research and Practice: A University Project for a Zero-Energy Building in Oman
}

\section{Nikolaus Knebel}

German University of Technology in Oman (GUtech), Department of Urban Planning and Architecture, Muscat, Oman

\section{Abstract}

In Oman, like in all countries of the Gulf region, the building culture is in a crisis. The challenge to balance between a harsh outdoor climate and raised expectations for indoor comfort is not solved in a sustainable way, yet. Due to the availability of fossil fuel at very low costs, energy for cooling buildings is not used efficiently. This is not only wasteful, but also takes away the incentive to innovate. Consequently, the region's building boom of the past decades was a growth without progress. Neither has significant new knowledge been generated locally, nor has external knowledge

Corresponding Author: Nikolaus Knebel

nikolaus.knebel@gutech.edu.om

Received: 15 March 2019

Accepted: 25 May 2019

Published: 20 November 2019

Publishing services provided by Knowledge

(c) Nikolaus Knebel. This article

is distributed under the terms of the Creative Commons

Attribution License, which permits unrestricted use and redistribution provided that the original author and source are credited

Selection and Peer-review under the responsibility of the Architecture across Boundaries Conference Committee.

\section{G OPEN ACCESS} been transferred to build local capacity in the field of sustainable buildings. To break up this stagnation, The Research Council of the Sultanate of Oman (TRC) started in 2011 to fund a project in which the German University of Technology in Oman (GUtech) designed, planned, built, and currently operates and monitors a net-zero-energy residential building on its campus. This paper shows that GUtech's EcoHaus is not only in a building as a product, but also a process of generating and transferring knowledge by combining teaching, research and practice within one university project.

Keywords: zero-energy building, sustainable design education, Gulf region, Oman

The challenge of sustainable buildings today is that they are hardest to make where they are needed the most; that is in the countries of the so-called emerging markets. In these places a strong population increase and growing purchasing power unfortunately coincides with a weak building culture; an unbalanced or non-existent interaction between the multiple players and factors that are required to make a building successful: cities, citizens, clients, consultants, companies, contractors, craftsmen, climate, and culture.

The Sultanate of Oman is in a situation like this. The capital city, Muscat, has almost doubled its housing stock over the past decade, while the building culture remained on a low level of expertise. Figure 1 shows a typical urban design and building construction situation with oversized streets with low-rise buildings that have large windows regardless of orientation as well as construction methods in which a garden wall, an external and an internal wall are not differentiated despite their very different performance 


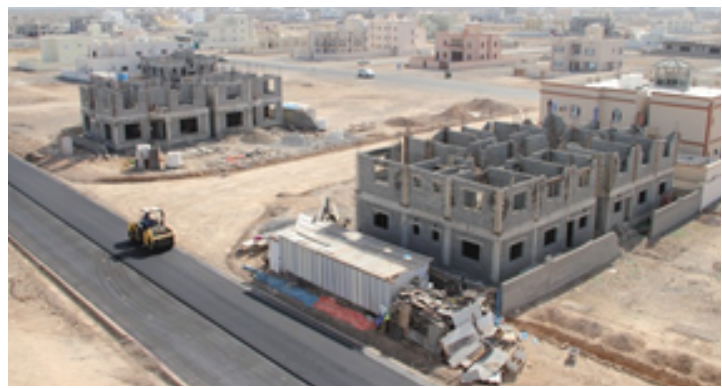

Figure 1: Todays typical design and building construction methods in Oman are inappropriate for the hot climate.

requirements. To overcome this crisis, it is important to develop and test prototypical sustainable buildings. But what is needed in addition to this is a thorough education for the next generation of architects to be able to develop a sustainable building culture in its own right.

The project presented in this paper, the EcoHaus of the German University of Technology in Oman that eventually will serve as the university's guesthouse, is a two-storey house of approximately 250sq.m that aims at a net-zero-energy performance. It was built within a design competition held by The Research Council of the Sultanate of Oman (TRC) from 2011-14 and is being monitored since. The aim of the project, however, is much wider than just building a house. It is an attempt to break through the gridlock of the stagnant building culture in Oman (Knebel, 2015) and trigger the finding of locally adequate ways of building energy-efficient and sustainable buildings and at the same time educating the next generation of architects on a real project. This paper presents the various facets of teaching, research and practice that emerged from the project and shows how the fluent borders between these realms were crossed back and forth.

\section{From Teaching to Practice: Student Designers Become Professional Architects}

The competition format demanded, firstly, that the project had to be developed by students, and secondly, that it had to be submitted in a very short period of time. Because of these constraints a learning context was created that enabled beginners of an architectural and urban planning undergraduate programme to carry out the task very quickly. Thus, direct experience and personal interaction was chosen over scholarly studies.

Students went on a series of excursions to the built heritage of Oman - mainly oasis settlements made of earthen constructions that are vernacular zero-energy buildings, 
and participated in a number of workshops with internationally acknowledged professionals from the field of sustainable design, construction and engineering as well as a peer-to-peer session with the team of the RWTH Aachen university's 2012 Solar Decathlon student team. The consequence of this process can be clearly seen in the student project that was finally selected for implementation, as the design shows a very intuitive approach to designing a zero-energy building. Rather than undertaking a deep research phase prior to giving form the design process starts with a simple but strong gesture of making space: two hands forming an enclosure that protects an interior zone from its exterior environment. From this gesture derived the round form of the EcoHaus (Figure 2). Eventually, the building was placed such that it turned the protective enclosure towards the east and west from where the impact of the sun is strongest as well as to the south from where the noise from the nearby highway is loudest. The cylinder's main opening is to the north to allow views to the campus and to catch the wind from the prevailing direction. (Figure 3).

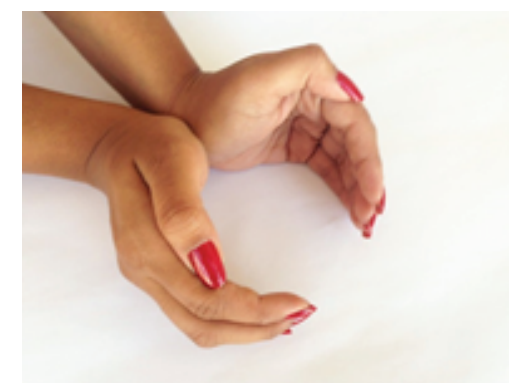

Figure 2: The initial design idea for the EcoHaus derives from an intuitive approach expressed by a hand gesture showing a protected space.

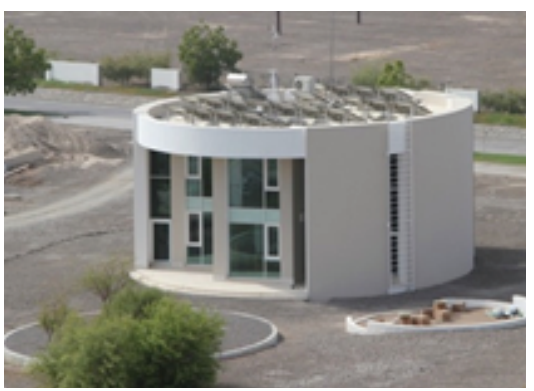

Figure 3: View from the north to the EcoHaus on the GUtech campus.

Once the schematic design was developed and the grant from The Research Council for actually building the house was awarded (Figure 4), the university decided to not out-source the planning and supervision works of the project, but instead to build up competence in sustainable design and construction methods in-house by forming a team of faculty and graduates, so that a new generation of competent architects would start growing from this project. This was in contrast to common practice in the region 
where progressive projects are run by international design consultants and project managers who come and go with their knowledge; what remains in the end is the project, but not the process skills.

Consequently, two graduates were hired to work on the project right after their completion of the university's undergraduate programme (Figure 5). In a very challenging learning-on-the-job situation they were given responsible roles, which they carried out under the guidance of professors. "In the two years that I worked on the EcoHaus I had responsibility for so many aspects of the project, from designing landscaping with native plants, building an ecological water treatment wetland, producing and procuring local and natural materials, to supervising the site with various trades and people from many cultures. Through this work I was exposed to real life early on in my career and still benefit from this experience in my job today in a multi-disciplinary company." reflects Rumana Al Othmani, one of the graduates that joined the team (Kamanpouri, 2018).

In addition, four undergraduate students supported the EcoHaus team as interns during their semester holidays. Through this tough set-up the students and graduates became not only professionals very quickly, but are now seen as champions in their field by the building scene in Oman. "Working as a student (...) on the EcoHaus project made me aware of the possibilities for a more environmentally- friendly architecture in Oman. Now, in my work in the office that I set up with my cousin I feel confident to propose the use of solar power or grey water systems to clients. The fact that we used these elements successfully in the EcoHaus gives an immense credibility to my suggestions." says Nujaida Al Maskari, who was one of the students in the initial design studio and later an intern during the construction phase of the EcoHaus (Kamanpouri, 2018).

In a building culture that is stagnating for many reasons such breakthroughs in skilled local manpower is invaluable. Even more so because all student team members were female and in the cultural context of the Gulf countries would otherwise not have had the exposure to site works and might not have been trusted with responsibility as juniors. It is not without irony that the team won the trophy for "Best Architect" in the Oman Construction Week Award 2015 even though it was never established as an official architecture office.

\section{From Teaching to Research: Student Designs Are Veri- fied Through Simulations}

In order to move from the intuitively discovered form of the Ecohaus to a scientifically justified performance of the house, a retroactive research and post-design rationalization 


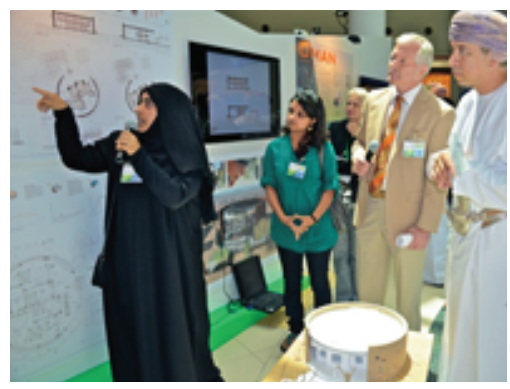

Figure 4: A student team presents the EcoHaus design to the mayor of Muscat and is awarded the first prize for the best design concept.

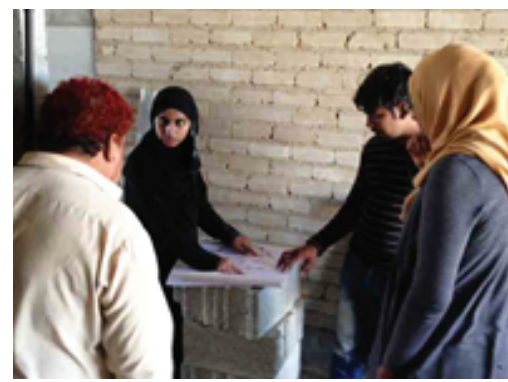

Figure 5: Graduates supervise the EcoHaus construction site and manage material procurement.

was necessary, even though this is an unusual order in a planning process. Transsolar, a climate engineering consultancy from Germany, held a workshop for students on energy-efficient designs and did several studies together with the GUtech team. A study through a one-zone thermal model of the building with the programme WUFI informed the construction system and material choice in that it showed that the intended solid mud-brick exterior wall would not perform adequately and thus a higher thermal resistance could only be achieved with a cavity wall, for which a light-weight pumice-andconcrete block on the exterior layer, a loose-fill insulation of perlite in the center layer, and a heavy compressed earth block (CEB) for thermal mass on the interior layer were used. Finally, the mechanical engineering system was informed by a study that showed that the main factor for energy consumption was the dehumidification of the very humid outside air in summer. Therefore, the air-exchange was minimized by only providing the hygienically necessary air-exchange and thus switching from a convective to a radiant cooling system. The sensible loads are carried by a hydronic system of chilled ceilings where as the latent loads are carried by a minimized air-handling system (Figure 6,7).

One master thesis student from RWTH Aachen's EON Energy Research Centre joined the team in Muscat early on and developed the specifications for the dimensions and layout of the photovoltaic system (Tschöp, 2012). Another RWTH Aachen student of Mechanical Engineering did a master thesis project and built a digital model to simulate the performance of the house-as-built was developed. This digital model was used to 
benchmark the simulated performance of the house with that of a reference house. The results show that during the summer months, when active cooling is imperative the EcoHaus uses $30 \%$ less cooling energy than a building that is constructed as per the Muscat Municipality regulations, and it uses $60 \%$ less cooling energy compared to a building with simple construction methods that are used in most projects (Pech, 2015). While these findings verify the decisions taken for the design and construction of the EcoHaus, it also shows that if only the current building regulations were enforced, a large saving in energy consumption could already be achieved.

Yet another master thesis project developed and dimensioned an adsorption cooling system for the EcoHaus. With this switch from an electro-mechanical chiller driven by electricity from a photovoltaic system to an adsorption chiller that is driven by a solar thermal collector would result in a cooling system that runs almost without electricity. However, the limitation is that in order to run the adsorption chiller in an efficient way the provided temperature of chilled water would be sufficient to supply the chilled ceilings, but not the air-handling unit. Thus a dual system was recommended, which, if installed, would still be a significant saving in electrical consumption for cooling buildings. Unfortunately, the installation of this component of the project is on hold due to a lack of funding (Dölz, 2015).

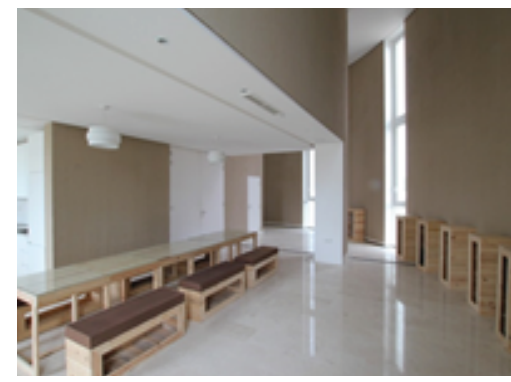

Figure 6: The interior view shows the mud brick walls, the chilled ceilings and the inlets for reduced air-flow.

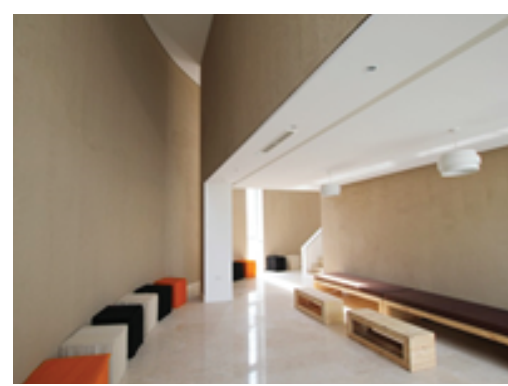

Figure 7: The interior view shows minimal lighting installed as well as furniture made from recycled materials and locally produced carpet cubes. 


\section{From Practice to Research: A Real Building's Perfor- mance Is Monitored On Site}

Having an experimental building on campus - not as a temporary installation, like in a Solar Decathlon project, but as a permanent facility - creates excellent opportunities for students to carry out hand-on research. As a first step, students from the Urban Planning and Architecture programme installed a data acquisition system (DAS) that includes an exterior weather station and seven sets of sensors to monitor the indoor thermal comfort in various zones of the house as well as the electricity demand of the cooling system and appliances and the supply from the photovoltaic system.

One undergraduate thesis student from the Computer Science study programme is developing a building management system to control the cooling system settings, while another is programming software to manage the incoming data to display the performance of the house graphically (2019).

Several students from the Environmental Engineering undergraduate programme wrote their thesis about monitoring acoustic and visual comfort in the house as well as measuring the indoor air-quality $(2017,18,19)$. They found that the optimal orientation of the house in terms of minimizing the heat gains from the East and West sides through fully opaque facades as well as shading the South windows with external shades does also lead to a visually very comfortable distribution of daylight. They also found that the air-intake through the Air-Handling System's inbuilt filter provides an indoor air-quality that is much superior to the outside conditions of a dry and dusty environment. However, the acoustic measurements showed that the location of the technical room in the center of the house produces noise pollution beyond comfort levels and a better insulation of the doors and less noisy pumps for the cooling system are to be installed (2017).

Another thesis student in this programme evaluated the performance of the constructed wetland, a water treatment system, that receives all sewerage (black) water from the house. The findings confirm that such a natural, low-maintenance and lowenergy is effective enough to provide effluent water that is suitable for irrigating a garden or a green roof (2017) (Figure 8).

Further, the electricity yield from the photovoltaic panels was monitored over three 12 month periods (Figure 9). Benchmarking this recorded yield against the simulated yield showed that the PV system performed as expected. A record of the cleaning schedule for the PV system demonstrates that a three man-hour monthly manual cleaning effort is sufficient to achieve this satisfactory performance. These are important findings to underline the still often doubted feasibility of PV systems to power small residential 
housing units in the Gulf region. In the same study an optimization of the PV system was discussed concluding in the recommendation to install the panels with a $0^{\circ}$ angle instead of the usual $25^{\circ}$ angle in order to provide peak yields during peak demand times in summer (Knebel \& Wassmer, 2019).

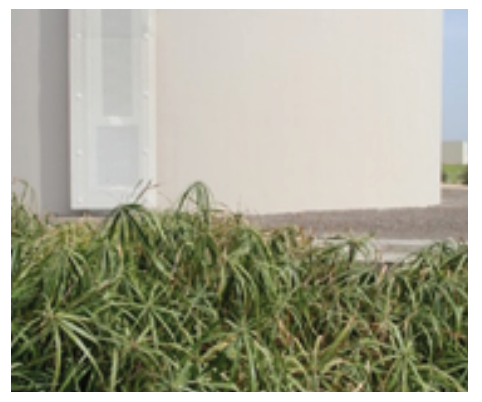

Figure 8: The constructed wetland for natural water treatment installed behind the EcoHaus.

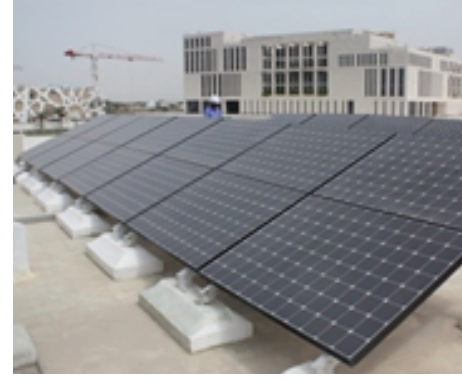

Figure 9: The roof-mounted PV system with ballasted racking on the roof.

\section{From Practice to Teaching: Construction Is Observed and Practiced}

The interaction between teaching and practice was not only in one way as described above. It also worked by turning the site into a classroom for several courses, which could be done because the EcoHaus was built on campus within eyesight of the university's teaching facilities. Students from the undergraduate program in urban planning and architectural design were regularly updated on the progress of works and visited the construction site often. The construction manager gave a course on site processes, and companies that donated or provided cost-priced materials, such as e.g. Oman Concrete Products or REHAU / MyWindow invited students for factory visits to better understand their materials and products in their full lifecycle. Bauer Nimr LLC gave a design workshop to integrate their constructed wetlands for natural water treatment into the building, and Gyproc facilitated a hands-on workshop in building dry-wall systems with locally produced and health- oriented panels. In another workshop, students built 
furniture from recycled construction timber. In a building culture in which craftsmanship is not present anymore and rarely any product is repaired nor recycled and students of architecture have not often worked with their hands such experience of the real making of architecture are particularly important.

The EcoHaus project was a starting point in yet another project that spans from teaching to research. Out of the initial idea to build the EcoHaus with earthen construction came the set up for the production of sundried, compressed earthen blocks (CEB) on campus; a material that until today is not available in the building material market in Oman (Figure 10). (Un-)fortunately, a few thousand CEBs too many were produced so that this material could be made available for learning and testing on an experimental building yard on campus that was set up by two professors for a design studio on building and designing with natural materials (Knebel \& Schlesier, 2015). Students not only designed but also themselves built a small pavilion of CEB masonry walls and of rammed earth (Figure 11).

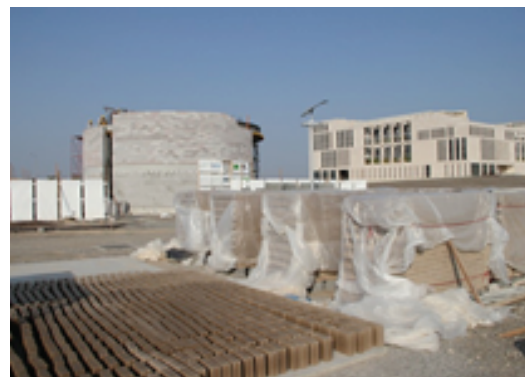

Figure 10: Production yard for compressed earth blocks set up on campus next to the EcoHaus site.

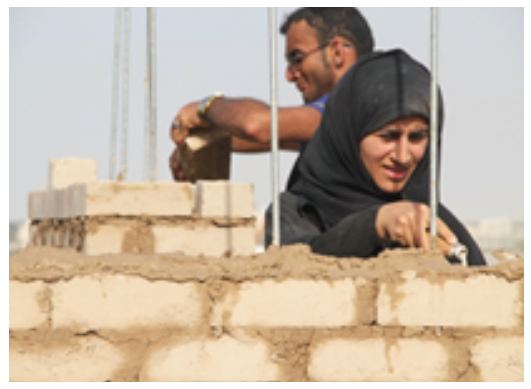

Figure 11: Students practicing construction with natural building material, compressed earth blocks.

\section{From Research to Teaching: Successful Precedents Are Analyzed and Learned}

Teaching always contains an element of method as well as of content. When teaching the design of climate-adapted buildings in a context like in Oman, where there is a very limited range and acknowledgement of exemplary architecture projects for modern and 
urban functions, a design teacher can well transfer methods of design thinking from one cultural context into another (even though the limits of this transaction would need to be discussed as well), but the actual content that is embedded in exemplary case studies cannot be transferred across borders. Thus, these exemplary cases that can serve as teaching material must be found in the context itself.

In an academic research into what can be learned from modernist and contemporary architectural designs built in the Gulf cities over the past half century a set of case studies was selected and analyzed according to their capacity to provide passive cooling in the hot climate of the region (Knebel, 2019). These findings are articulated in the form of patterns, a format that is seen as an appropriate way of communicating knowledge about "proven solutions for recurring problems" in architecture (Alexander, 1977).

In several courses on architectural analysis, undergraduate students learned to extract such patterns from given case study projects so that they themselves can build up a repertoire of references from the specific context of the climatic region of the Gulf countries rather than just depending on foreign literature (Figure 12). Further, most of the analyzed buildings were also experienced first-hand and visited on excursions to the United Arab Emirates (2016), Qatar (2017) and soon to Kuwait and Bahrain (2020) (Figure 13). One of these excursion was undertaken by a mixed group of architecture students from the German University of Technology, Oman, together with master students from TU Munich, Germany, (Chair of Building Technology and Climate Responsive Design, Prof. Thomas Auer), which lead to a very fruitful intercultural exchange through which the sometimes different evaluations of what a successful solution is became apparent in discussions.

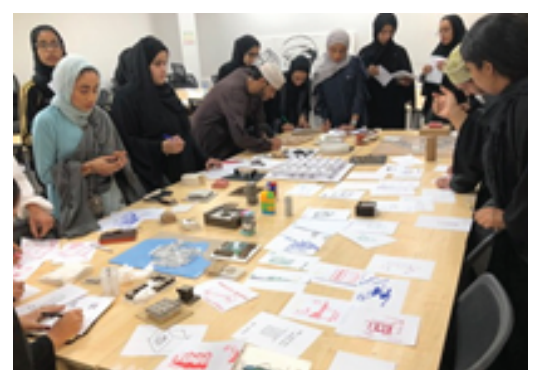

Figure 12: Students analyzing successful passive cooling strategies in case study projects. 


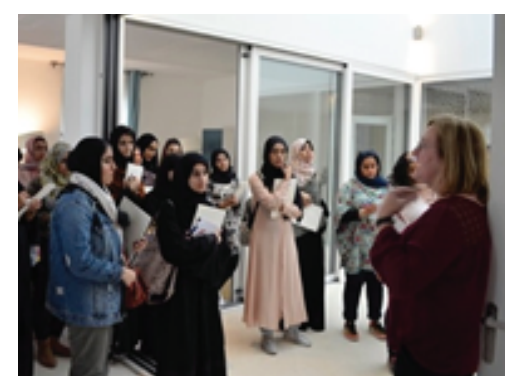

Figure 13: Visiting the Qatar Passivhaus Project in Doha (Qatar Green Building Council).

\section{From Research to Practice: New Designs Are Proposed For Real Clients}

The knowledge that is gained from dealing with the EcoHaus project in the many facets that are described above is applied in new design projects that were commissioned by private and institutional clients. These projects are an opportunity to explore how the persistent pursuit of passive cooling strategies fundamentally changes the typologies of buildings, which is shown in the designs for a villa (2015-16), a clinic (2017), a multistorey apartment tower (2018), as well as an office complex (2019) (Figure 14,15). Here the focus is on creating shaded and ventilated outdoor spaces within a building's volume, avoiding direct sunlight on any glazed facade, while providing spaces that are evenly lit with natural daylight and are cross-ventilated for a maximum period of the year. In these projects, yielding electricity from photovoltaic panels is as much a standard designintegrated element as is a natural water treatment system that was also applied in the initial EcoHaus project.

Further to designing for real clients the knowledge from the EcoHaus project is transferred to student projects that aim at real building practice. For example, the student group of the Ecole d'Architecture et de Paysage de Bordeaux invited the EcoHaus team leader for a workshop (2016) to discuss ideas such as e.g. using mud bricks in the interior for thermal mass and green roofs to mitigate the exterior micro climate in the hot environment of the region for their design of the Solar Decathlon Middle East project "Baitykool" that was eventually built in Dubai in 2018. In addition, a group of the university's architecture students was mentored in a design process that focusses on natural, local and recyclable materials as well as on creating shaded and ventilated outdoor spaces at low costs for the university's art club building. Starting to build another energy-efficient and eco-friendly building on campus would bring the EcoHaus project full circle. 


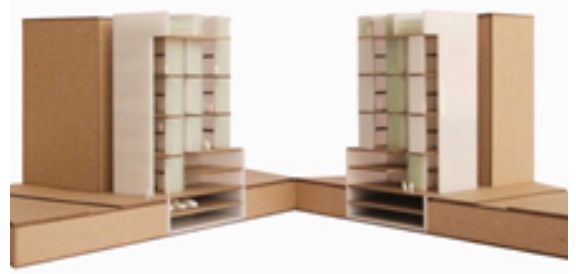

Figure 14: Schematic design for a multi-storey apartment tower in Muscat (front view of section model).

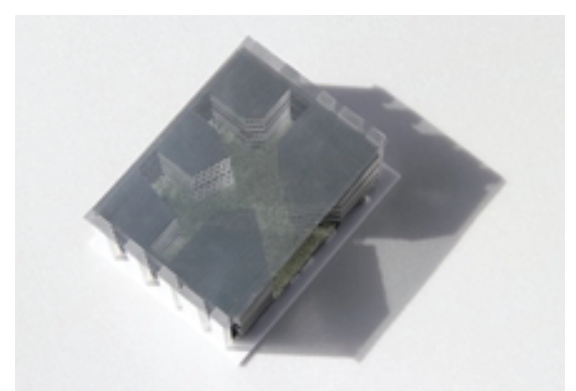

Figure 15: Schematic design for an office complex in Madinat Al Irfan (top view).

\section{Across Borders}

By moving between teaching, research and practice in the various ways described above, the GUtech's EcoHaus project demonstrates that the borders between knowledge generation, knowledge transfer and knowledge application are fluid. It also shows that the borders between a university's various faculties as well as the industry's many professions are constantly crossed in order to make a project like this happen. And it is an example for an intercultural exchange between Omani and German team members, experts and project partners.

\section{Funding}

The EcoHaus project was funded by a grant from The Research Council of the Sultanate of Oman as well as through university budgets and industry donations.

\section{Acknowledgement}

The EcoHaus project is a major teamwork effort. The acknowledgements would range very far, but are here limited to the activities mentioned in this paper: Assoc. Prof. Martin Werminghausen who lead the initial design studio; GUtech graduates and team members Rowa El Zain and Rumana Al Othmani as well as students Shaharin Hossain, 
Amna Al Sharji, Aya Al Balushi, Nujaida Al Maskari; Prof. Matthias Rudolph and Christian Frenzel of Transsolar; Prof. Eike Roswag and Prof. Dr Christof Ziegert of ZRS; Daniel Jung of New Innovative Technologies; Wilfried Hofmann of bauplus; Dr Walter Mittelbach and Michael Dölz of SorTech; Prof. Dr Michael Modigell and Fabian Pech; Rita Stabenow, Pia Auferkorte and Georg Tschöp from EON Energy Research Centre; Assoc. Prof. Karsten Schlesier who collaborated on the building yard; Raffaela Betz for the excursions; Dr Hind Barghash from the Engineering Department and Ali Al Humairi from Computer Science; Felix Heusch who helped to draw the design patterns; Christina Cernovski, Carmen Neuhaus, Felix Huebbers, Maryam Abdu, Harindren Parmahamsa and Ricky Vinayachandran who worked on the new design projects; Mohamed Al Salmi and the facility management team of GUtech; and Mike Wassmer of LiveToZero who is connected to the competition and monitoring of the project in various ways.

\section{Conflict of Interest}

The author has no conflict of interest to declare.

\section{References}

[1] Alexander, C. et al (1977): A Pattern Language. New York: Oxford University Press

[2] Knebel, N., (2015): Lessons from the GUtech ECOHAUS. Outlook for establishing sustainable building practices in Oman. in: TRIALOG 07/2015

[3] Pech, F. (2015): Energy Balance of an Energetically Neutral Building for the Oman Eco House Design Competition by Modelling and Simulation. Unpublished Manuscript of Master Thesis at RWTH Aachen, Aachener Verfahrenstechnik, Mechanical Process Engineering, Prof. Dr M. Modigell

[4] Dölz, M. (2014): Implementierung der Adsorptions-kältemaschine "eCoo" in die Softwareumgebung Polysun Unpublished Manuscript of Master Thesis at Fachhochschule Nordhausen, Fachbereich Ingenieurwissenschaften, Studien-gang Systems Engineering, Prof. Dr T. Schabbach

[5] Kamanpouri, H. (2018): Cool(ing) Designs for Hot Climates. In: 48 Years of Glorious Omani Renaissance. German University of Technology. Muscat: Oman Observer Press, p. $143 \mathrm{ff}$

[6] Knebel, N., Schlesier, K. (2015): Earth, Timber and Khous. Learning to Construct and Design with Natural Materials 
[7] Knebel, N., Wassmer, M. (2019): Monitoring, Evaluating and Optimizing the Monitoring, Evaluating and Optimizing the Energy Supply of a Photovoltaic System of a Zero-Energy- Building in Oman: Case Study of the GUtech EcoHaus. Paper published in the proceedings of the CATE19 Comfort At The Extremes conference, Hariot Watts University Edinburgh/Dubai.

[8] Knebel, N. (2019): Identity through Efficiency. (Re-)Discovering Passive Cooling Strategies as an Architectural Idiom for the Gulf Region. Paper published in the proceedings of the CATE19 Comfort At The Extremes conference, Hariot Watts University Edinburgh/Dubai. 